\title{
Job Involvement and Knowledge Sharing Dependence on Organizational Citizenship Behavior
}

\author{
Dr. Henry Jonathan ${ }^{1 *}$, Sebastian Cyprian ${ }^{2}$, Robert Majura ${ }^{3}$ \\ 1 (HRM Department; Local Government Training Institute, Tanzania) \\ 2 (HRM Department; Local Government Training Institute, Tanzania) \\ 3 (CD Department; Local Government Training Institute, Tanzania) \\ P.O BOX 1125, Dodoma, Tanzania \\ *Email: h3y77@yahoo.com
}

This research is financed by Research and Consultancy Fund (RCF) offered by Local Government Training Institute (LGTI) Dodoma; Tanzania. Among several purposes; RCF focuses on improving research and consultancy activities in LGTI academic departments

\begin{abstract}
Theory of Reasoned Action (TRA) was employed in this study as fitting theory for investigating determination of Knowledge Sharing behavior. TRA is a choice theory that elucidates drive of executing behavior by emphasising the definite processes that employees follow to take choices. TRA takes an employee drive to execute behavior by utilizing the concept of intention to execute behaviour. A TRA model was crafted on three variables [(Job Involvement (JI); Organizational Citizenship Behavior (OCB) and Knowledge Sharing (KS)] and empirically investigated Job Involvement - Knowledge Sharing association. Then, OCB moderating role in this association; was tested as an extension variable to the traditional TRA model. Questionnaires were completed on self-rating fashion where 421 employees in Local Government Authorities (LGAs) formed study sample. Hayes (2004) and Mod-Graph (Jose, 2013) approach was jointly employed to determine potential OCB moderation role in the study. Results suggested; Job Involvement - Knowledge Sharing association was positive in nature; thus, both changes in tandem. Further, Job Involvement - Knowledge Sharing association strength depended on the third variable namely OCB; hence, OCB affected the strength of the independent and dependent variable association in the study. Implications for practice and future study were composed subsequent to conclusions.
\end{abstract}

Keywords: Tanzania, Local Government Authorities, Job Involvement, Organizational Citizenship Behavior, Knowledge Sharing

DOI: $10.7176 / \mathrm{IKM} / 10-7-06$

Publication date: November $30^{\text {th }} 2020$

\section{Introduction}

Knowledge refers individuals' competence on specific field acquired through tailor made training and observation when practicing or experiencing (Mahmood et al, 2011). Knowledge is perceived as set of information and understanding obtained through practical experience which is fundamentally existing in respective individual (Nonaka, 1994). It is known to be essential corporate resource that enables retention of sustainable competitive advantage in a competitive market share (Aliakbar et al, 2012). Knowledge Sharing (KS) is described as the process of handing over knowledge from an individual in knowledge possession to individuals in deficit (Hwie \& Byung-Choon, 2003). Existing research reported stream of knowledge sharing benefits including but not limited to decreased production costs; improved team performance; and enhanced corporate innovation capacity (Collins \& Smith, 2006). In respect to these likely benefits; some organizations invested substantial amount of resources 
into Knowledge Sharing (KS) initiatives (Wang \& Noe, 2010). Conferring Wang \& Noe; investment is geared to enable knowledge data gathering, storage and delivery to desired destinations. Yet, difficult in knowledge sharing prevails because knowledge is acquired and possessed by individuals (Chow \& Chan, 2008). The challenge to share knowledge is that; it is voluntary endeavor and sharing is conceivable when bearers are prepared to do so (Mahmood et al, 2011). Sharing difficulty is primarily worse when bearers perceive possessed knowledge as treasured assets and free knowledge sharing is against their natural preferences (Hsu et al., 2007). While Knowledge Sharing received stream of researches; most findings are devoted and restricted in private sector; with little findings in public sector (Ahmad, et al, 2013). Empirical studies have associated lack of findings of practical importance in public sector with lower pace discharge of public service delivery (McAdam \& Reid, 2000). Similarly, several other reasons have been advanced to explain as to why lack of researches directed to public sector. Ahmad, et al, (2006) suggested most of researches are inclined to private sector because business mission leads them in searching for predetermined profit margin and competitive advantage. Unlike private sector; public sector is locked in not for profit syndrome (Nurin, 2012). According to Ahmad, et al, not for profit syndrome has thrown knowledge sharing in public sector into infancy pool.

Despite draught of Knowledge Sharing findings in public sector; some authors have reported Job Involvement Knowledge Sharing relationship. On previous studies footings; findings indicated positive association between Job Involvement and Knowledge Sharing [(For instance; Rehman et al., (2011); Probst (2000); Eman \& Din (2015)]. Ten \& Sun, (2011) claim Job Involvement may lead employees acquire self-confidence and influence to share possessed work knowledge as opposed to inadequate job involvement employees. Further; reviewed findings suggested OCB moderates the association between Job Involvement and Knowledge Sharing [(Hoshyar et al, (2017); Teh \& Sun (2012); Ueda (2011); Thiagarajan \& Kubendran (2012); \& Eman \& Din (2015)]. This is to say, they found active interaction (positive in nature) effect caused by OCB in the relationship under investigation (Teh \& Sun (2012) indicated; the effect of Job Involvement on Knowledge sharing differs at different values of OCB. Thus, OCB offered an enhancing effect towards explaining Knowledge sharing namely moderating effect. Though some studies have reported OCB moderation in Job Involvement - Knowledge Sharing association; there are evidence of criticisms. For example; Dubinsky \& Hartley, (1986) reported insignificant Job Involvement impact on Knowledge sharing behavior. Such evidence; puffed moderating reasoning based on Haye (2004) and Baron \& Kenny, (1986) research models. In addition; Husain \& Husain (2013) indicated insignificant interaction effect caused by OCB in Job Involvement - Knowledge sharing behavior; proposing more investigation in the area. Thus, evidence in reviewed literature shown conflicting and incomplete empirical backing (in public sector) in Job Involvement - Knowledge Sharing association; a moderating role of OCB.

On the other hand; quite huge number of researchers employed Theory of Reasoned Action (TRA) in predicting Knowledge Sharing using various antecedents. For instance; Mahmood et al, (2011); Rahab \& Wahyuni, (2013); Tlou, (2009); Hoshyar et al, (2017); Teh \& Sun, (2011); Aliakbar et al, (2014); Wang \& Noe (2010) just to name some. Though successful; some critics have been extended on TRA application. For instance; Hagger, (2019) questioned sufficiency of attitudes and subjective norms to explain behavioral intentions and actual behavior as direct variables. He maintained; TRA simplicity and ability to explain behavior needs vigorous investigation. As 
remedy; researchers proposed TRA model to introduce other variables into the model that may strengthen variances prediction in intention-behavior relationship. In other words, TRA model to incorporate other constructs like moderators to address simplicity, insufficiency and variance adequacy issues (Sheeran \& Webb (2016); VanBree, et al. (2013); Sheeran \& Conner (2017). This study concluded four issues from the reviewed literature. One: Though important; Public sector; is just commencing to appreciate the utility of knowledge sharing to quality and superiority of service delivery. Researches and findings into public sector are still developing and lacking. Two: literature put into overt, conflicting, incomplete and limited current empirical backing on Job Involvement Knowledge Sharing association; a moderating role of OCB. Three: TRA has been intensively used to predict Knowledge Sharing behavior. Nevertheless, it has received adequate application criticism including sufficiency, simplicity and ability in predicting behavior. Four: Huge researches have been conducted across the global; yet; such researches are still at infancy and limited in Tanzanian context. These limitations supported the rational decision for researching the area in Tanzanian Local Government Authorities (LGAs). As such, this study seeks to fill this gap by investigating Job Involvement - Knowledge Sharing basing on Theory of Reasoning Action (TRA). It extends the TRA by introducing moderating variable (OCB) in the attitude - intention -knowledge sharing causal relation. In doing so; the following questions will be addressed: -

1. What is the nature of relationship between Job Involvement (JI) and Knowledge Sharing (KS)?

2. Does Organizational Citizenship Behaviour (OCB) play moderating role in Job Involvement Knowledge Sharing relationship?

\section{What are the TRA extension remedies? (if any)}

\section{Theoretical Background}

\subsection{Knowledge Sharing in Public Sector}

Public sector in literal meaning covers not for profit corporate' which include executive agencies, Parastatal, State Owned Enterprises, LGAs, Military departments and Ministries, Departments and Agencies (MDAs) operating to deliver public services (Nurin, 2012). Knowledge sharing is equally vital to both public and private organization; thus, modern public institutions employ knowledge sharing measures as driving force to quality in service delivery (Milbraith, 1989). In quality footings, knowledge sharing has been recognized as utility in enhancing quality in service delivery to the community (Zhang et al., 2006). As such public institutions grasp innovation and active service delivery force through decent knowledge sharing management (Chen \& Hsieh 2015). Despite this importance, knowledge sharing has established inadequate attention in public sector as opposed to private sector (Chen \& Hsieh 2015)

Researches indicates most findings of practical importance have been conducted in private organizations; leaving counterpart public sector with little findings and implications on knowledge sharing (Ahmad, et al, 2013). It is not shocking, therefore, some of public service delivery discharged at significantly lower pace compared to private sector (McAdam \& Reid, 2000). Some authors went to the extent of saying; public sector is commencing to appreciate the utility of knowledge sharing to quality and superiority of service delivery (Taylor, 2002). But the importance of knowledge sharing in public sector is vivid; as it has fundamental rank not only in managing public 
affairs; but also, service delivery in particular (Lodhi \& Mikulecky 2017). According to Lodhi \& Mikulecky; when knowledge sharing management is magnificent; it fosters institutional operations by improving employees' attitudes towards desired organizational outcomes. However, if knowledge sharing management is disappointing; lapses and exposure is obvious and traditional outcome. Pivotal question is why knowledge sharing findings mostly in private sector as opposed to public sector. Some authors have associated this shortfall with business mission across private and public sector. Unlike public corporates; private corporates focus in business mission to constantly improve profit margin and sustain competitive advantage in market share (Ahmad, et al, 2006). Such mission receives little attention in public corporates on account of not for profit syndrome (Nurin, 2012). This has thrown knowledge sharing in public sector into infancy pool; more and vigorous researches are of essence (Ahmad, et al, 2006). To address this gap; this study explored the moderating role of OCB in the impact of Job Involvement on Knowledge Sharing in Tanzanian LGAs

\subsection{Job Involvement and Knowledge Sharing}

History suggests Job Involvement concept was crafted and introduced in research field around 1965 by Lodahl \& Kejiner. The concept came on; following huge number of studies in the area; where eventually an acceptable definition was lounged. Alternatively; Knowledge Sharing in contemporary organizations is essential and prerequisite for strengthening innovation and organizational wellbeing (Oscar, 2011). According to Oscar; Knowledge sharing links the source of knowledge and corporate where knowledge is not only needed but also applied and exploit value in the competitive markets. Fairly, wide studies have reported Job Involvement Knowledge sharing relationship. Job Involvement may strengthen organizational outcomes (Including Knowledge Sharing) through directing employee to be more engrossed with their jobs and making committed efforts to corporate goals (Carson et al. 1995).

In an empirical study; Teh \& Sun (2011) reported a positive association between Job Involvement and Knowledge sharing. Teh \& Sun, claim; Job Involvement may lead employees acquire self-confidence and influence to share possessed work knowledge as opposed to inadequate job involvement employees. Further, Rehman et al., (2011) found employees who reported high in Job Involvement are more likely to share their knowledge with peers. It was reasoned; employees who reported significant Job Involvement are more satisfied with their jobs and develop engagement spirit which is fundamental to knowledge sharing (Carson et al. 1995). In a study; in manufacturing sector; Probst (2000) produced findings that; Job Involvement positively impact knowledge sharing behavior; when intent to share behavior is impacted as well. An obvious claim is Job Involvement may create happiness environment which is ultimate in intent to share knowledge and actual sharing behavior (Constant et al., 1994). In addition, Eman \& Din (2015) contended the impact Job Involvement has on knowledge sharing behavior at work. They found direct and positive relationship between the two constructs. It was maintained that; employee's psychological attitude such as job involvement may persuade employees' intention to share knowledge to those in need (Ten \& Sun, 2011). It can be reasoned; Job Involvement influence employee's cognitive readiness to perform knowledge sharing by making combination of positive attitude and subjective norms functional (Fishbein \& Ajzen, 1980). 


\subsection{OCB as Moderator}

According to Cohen et al, (2003); a given variable may be purported to operate as a moderator; if it affects the strength of the predictor-dependent relationship. In other words; the purported moderator has to cause interaction that leads to alter the strength of the variable association. Several studies have investigated Job Involvement Knowledge Sharing; Job Involvement - OCB and OCB - Knowledge sharing relationship. For instance; Ueda (2011) found Job Involvement positively associated with OCB. Hence; higher levels of Job Involvement goes with higher levels of OCB. Meanwhile; Thiagarajan \& Kubendran (2012); reported OCB is positively associated with Knowledge sharing behavior. Further; Eman \& Din (2015) found significant and positive association between Job Involvement and Knowledge sharing behavior. It is practical, therefore, to suggest there is OCB interaction effect in Involvement-Knowledge sharing behavior association namely moderating effect (Baron \& Kenny, 1986). Hoshyar et al, (2017) conducted a study on investigating indirect role that OCB play on Job Involvement Knowledge Sharing behavior. They found OCB play an enhancing role when Job Involvement predicted Knowledge Sharing behavior. In other words, Job Involvement caused lesser variances on Knowledge Sharing behavior when OCB kept on hold. And, improved variances were noted when OCB were in operation. According to Cohen et al, (2003); these findings concluded OCB moderating Role as it caused strength alteration when in and out of operation. Teh \& Sun (2012); assessed OCB interaction effect on Job Involvement - Knowledge sharing behavior engaging Information System personnel. They found active interaction (positive in nature) effect caused by OCB in the relationship under investigation. Stating otherwise; the effect of Job Involvement on Knowledge sharing differs at different values of OCB. Thus, OCB offered an enhancing effect towards explaining Knowledge Sharing namely moderating effect.

Literature proposes; positive job attitude such as JI have positive impact on OCB (Podsakoff et al. 2000). Of course, in obvious ways, it is because employees engross willingness to take more than assigned duties when they have positive attitude towards job (Bolino et al., 2002). It is also evident that employees high in OCB are more likely to engage Knowledge Sharing behavior (Hsu \& Lin 2008). Consequently, it is proposed that Knowledge Sharing behavior have positive association with OCB. Relatively good numbers of studies have investigated the impact of Job Involvement on Knowledge Sharing as well. For example, Eman \& Din (2015) found direct and positive relationship between the two constructs (Job Involvement and Knowledge Sharing). It was maintained; an employee who holds higher levels of Job Involvement; normally; become positive and committed to share knowledge to those missing. Thus, Job Involvement and OCB forms interaction term that facilitate description of predictor (JI)-outcome (KS) association either (Preacher et al, 2007). Conceivably, the effect of predictor variable (JI) on outcome variable (KS), in this case, depends on the degree of strength in interaction terms. Much as past literature suggests interaction term in the Job Involvement - Knowledge sharing; OCB may register a moderating variable in this study. However; reported standing for OCB likelihood to moderate Job Involvement - Knowledge Sharing relationship; is not absolutely free from critics from other cultural contexts. For example, some studies reported Job Involvement impact on some attitudinal based variables such as Knowledge Sharing desire was insignificant (Dubinsky \& Hartley, 1986). This report should be a blow to moderating reasoning based on Haye (2004) and Baron \& Kenny, (1986) research models. Further, Husain \& Husain (2013) reported insignificant interaction effect caused by OCB in Job Involvement - Knowledge Sharing behavior; proposing more investigation in the area. 


\subsection{Theory of Reasoned Action}

The existence of Theory of Reasoned Action (TRA) dates back in 1967 when it was first coined to predict the association between attitude and behavior (Ajzen \& Fishbein, 1980). Figure 1: present schematic form of the Theory of Reasoned Action. TRA was crafted following once in a while failure to determine behavior using classical procedures of attitude (Fishbein, 1993). The theory sits on the assumption that employees are not only lucid but also make orderly use of accessible information. Thus, employees contemplate consequences of their conduct's prior final decision on behavioral options (Tlou, 2009). Literary, TRA seeks to determine the association between belief, attitudes, intentions and behavior (Ajzen \& Fishbein, 1980). It suggests the pivotal factor for predicting employee's behavioral intention is attitude and subjective norms connected to the behavior of interest (Montano \& Kasprzyk, 2002). Putting in another way, the employee's choice as to whether or otherwise, engross in certain behavior is dictated by intent to execute the behavior; which originate from subjective norm and attitude on the behavior under considerations (Yu et all., 2010)

On TRA attitude standings, TRA define as individual's defiance towards executing the behavior of interest (Ajzen \& Fishbein, 1980). It is the extent to which one feels positive in sharing knowledge to those in deficit (Bock et al. 2005). In other words, it accrues from behavioral belief and extent of positive or negative touch of an employee over intention to share knowledge across the corporate (Rahab \& Wahyuni, 2013). This is to say, employees' prospects to execute behavior under considerations gets stronger when facilitative attitude prevails (Fishbein, 1993). On TRA subjective norm standings, it clicks the extent to which an employee carries belief that individuals who exert pressure on peoples conducts expects them to execute behavior of interest multiplied by the degree of individuals' submission with each dependent referent (Fishbein \& Ajzen 1975). It is crafted from normative belief and covers employee belief that peers/relevant others expect joint engagement in desirable behavior (Rahab \& Wahyuni, 2013). In organizational rapports, relevant others; covers top, middle and lower management teams. By itself, it is ordinary smart employees would wish to obey with management team's prospects in knowledge sharing standards (Lee et al, 2001). Bestowing Lee, as employees are further motivated to imitate group norms; the further the attitude incline to group norms. Consequently, it is practical to speculate that subjective norms on knowledge sharing would encourage others attitude in the direction of knowledge sharing at work (Lee, 2005). On TRA intention to share relations, intention to share knowledge behavior refers the extent to which knowledge will be shared by individuals in question (Dennis (1996). It takes into considerations employees' subjective likelihood that they will execute certain behavior perhaps desirable by the corporate (Fishbein \& Ajzen 1981). The pivotal word here is individual intent which is described as employee's cognitive willingness to execute specific behavior. Stating otherwise, it is defined as individuals' plan of action and denote self-articulated motivation engage in behavior of interest (LaCaille, 2013,). Peslack perceive the same as the propensity and tendency to engross in the behavior which is actual by itself (Peslack et al., 2012). That said it is vivid that; joint influence accruing from

attitude, subjective norms and behavioral intent spans disciplines in determining behavior outcomes across organizations (Fishbein \& Ajzen, 2011) 


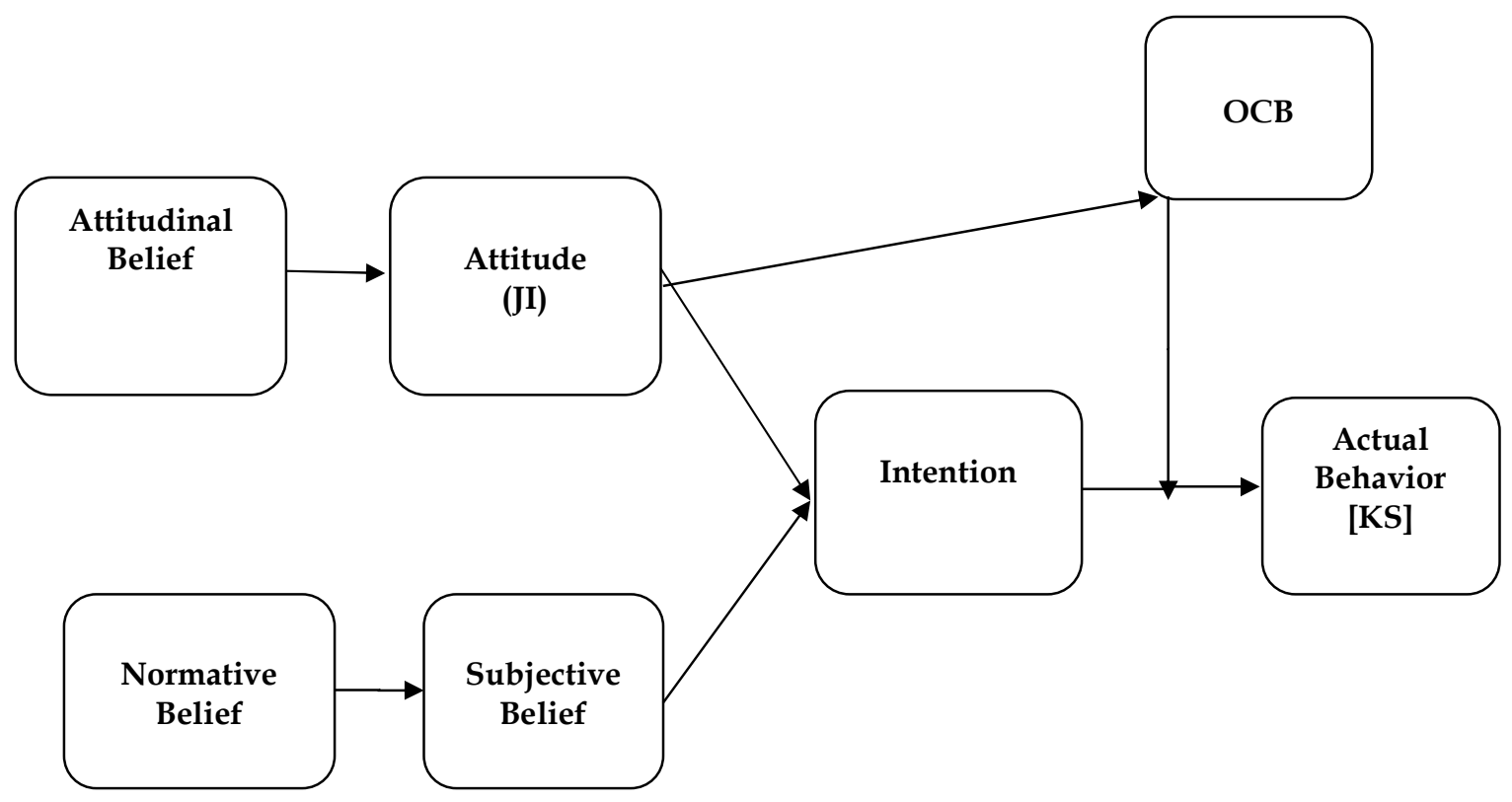

Figure 1: Theory of Reasoned Action (Ajzen \& Fishbein, 1980)

Employees' decisions to share knowledge in Local Government Authorities (LGAs) can be studied through the lens of TRA. Primarily, Job Involvement (JI) and Organizational Citizenship Behavior (OCB) are both attitudes important in determining organizational outcomes such as knowledge sharing behavior (Hoshyar et al, (2017). This feature, because employees high in both JI and OCB develop constructive job spirit which in turn triggers desired organizational outcomes (Rehman et al., (2011). Practically, employees who trust that important referent (eg supervisor or peers) are in the opinion that she/he should execute desired behavior (in this case Job Involvement) and he/she is motivated to conform with the said referent desires; will grip positive subjective norm (Tlou, 2009). Much as TRA adopts a causal relation that connect behavior and normative beliefs to behavior intention and actual behavior through attitude and subjective norms (Ajzen \& Fishbein, 1980); it sensible to suggest that employees are likely to engage in knowledge sharing behavior; if they evaluate positively others think they should engage in Job Involvement (Montano \& Kasprzyk, 2002). Equally important; if positive attitude is pivotal variable to knowledge sharing behavior intent and actual knowledge sharing (Hoshyar et al, 2017; Ajzen \& Fishbein, 1980); the propensity of sharing knowledge will be sturdy, if they engross decent Job Involvement attitude towards knowledge sharing behavior (Fishbein \& Middlestadt 1989). Precisely putting, positive attitude towards JI and OCB; and positive perceptions of norms for JI and OCB create intentions to actual knowledge sharing (Mahmood et al, 2011). It is practical to suggest therefore; using TRA, positive attitude towards Job Involvement and OCB (attitudes) are good predictor of intention and actual knowledge sharing behavior.

Despite TRA's acceptance, adequate quantity of critiques has been offered. One of the chief critics; is sufficiency of attitudes and subjective norms to explain behavioral intentions and actual behavior (Hagger, 2019). Additionally, the simplicity and ability to explain behavior has also been put TRA under scrutiny. Thus, there is a significant conclusion that TRA offer limited explanation of behavior. In response; authors suggested TRA to incorporate additional variables to have relatively comprehensive behavior explanation. For example; Steinmetz, et al. (2011) argued TRA to introduce other variables into the model that may strengthen variances in intention- 
behavior relationship. They precisely proposed introduction of moderation variables. Evidence suggested; significant number of respondents who reported intention to execute behavior; failed to execute intended behavior; putting questions to Intention-Behavior conclusions in TRA. Sheeran \& Webb (2016) noted useful intentionbehavior gap and proposed extension in the TRA constructs. This was supported by other literature; for instance; employees possessing sturdy habits, assessed by self-report and earlier behavioral occurrence, incline to display weaker or insignificant intention-behavior relationship (Van-Bree, et al. 2013). The treatment to this gap; is to involve moderators into the TRA model; to reinforce intention-behavior relationship (Sheeran \& Conner 2017). It is unfortunate, however, that OCB moderating effect on attitude - intention-behavior relationship has rarely been tested (Hagger, 2019)

\section{Methodology}

\subsection{Approach, Sample and Procedure}

Moderating effect studies normally involves quantitative and questionnaire-based approach such that constructs and variables can be quantitatively related (Salas-Vallina et al, 2017). Thus, this study employed the same approach. It was designed on postulation that OCB works as moderator following its reported buffering role in Job Involvement - Knowledge Sharing relationship. This suggests the use of data collected from non-managerial employees (Bogler \& Somech, 2005). According to Bogler \& Somech subordinate employees executes issues on the ground and thus stand a better chance to intensively describe OCB, Job Involvement and Knowledge Sharing at work. In response, data were collected from subordinate staff as opposed to managerial staff; given study nature. Questionnaires were administered in Tanzanian Local Government Authorities (LGAs) in four varied administrative zones namely Central, Coastal, Lake, and Southern zone. Respondents were requested to complete closed ended questionnaire organized in three scales that measured Knowledge sharing desire; Job Involvement attitude and perceived level of OCB. In aggregate, 357 employees were approached to complete predetermined questionnaire. Of course, on obvious ways, employees were given an option to submit the same day or suggest convenient time. Of 357 employees, $52.7 \%$ were males $(n=188) ; 47.3 \%$ were females $(n=169) ; 57.7 \%$ were age below $35(\mathrm{n}=206) ; 42.3 \%$ were age above $35(\mathrm{n}=151)$. Data collecting procedures adequately complied with ethical considerations as proposed by Bryman \& Bell (2000). For example; participants were made to understand that filling questionnaire was voluntary and that collected data were to be kept in solid confidentiality. Above all; procedures for requesting data collection permission was given passable priority. All these were possible following pre-departure brief training extended to data collectors.

Study sample were conveniently obtained on belief; it is fastest and affordable to secure bulky data in large organizations (Bailey, 2012). Technically, the sample was expected to be biased towards subordinate employees; though, there is no reason to suggest the sample inclined to subordinate as opposed to managerial employees. In fact, the nature of the study made it necessary to survey subordinate employees (Bogler \& Somech, 2005). Further, the sample had adequate coverage as it involved the same adequate number of subordinates across LGAs. Consequently, non-randomness and selection issues across prospects were contained (Blair et al., 2014). Data collecting procedures adequately complied with ethical considerations as proposed by Bryman \& Bell (2000). For 
example; participants were made to understand that filling questionnaire was voluntary and that collected data were to be kept in solid confidentiality. In addition; procedures for requesting data collection permission preceded entire data collection activity. All these were possible following pre-departure brief training extended to data collectors.

\subsection{Measuring Job Involvement}

Job Involvement is described as how employees are interested, entangled and occupied by organizational goals, cultures and assigned duties to perform (Joiner \& Bakalis, 2006). By itself, it is the degree to which workers are customarily interested in, identified with and preoccupied with assigned tasks (Kanungo, 1982). Bestowing Kanungo, Job Involvement is viewed as attitudinal state that replicates single dimensional cognitive response of respective worker. In its basics, it is considered as an attitude important for organizational Effectiveness (Hoshyar et al, 2017). This is due to the fact that; employees high in Job Involvement also possess job satisfaction, positive spirit which is key in positive organizational outcomes such as Knowledge Sharing Behavior (Carson, 1995). A scale regularly used to measure Job Involvement is that of Kanungo (1982). It had previously demonstrated good reliability ie Cronbach's alpha better than .70 (Karriker \& Williams 2009). Kanungo's scale included five constructs namely: - [1]. The most important things that happen to me involve my present job; [2]. Most of my interests are centered on my job; [3]. I have very strong ties with my present job which would be very difficult to break; [4]. I like to be absorbed in my job most of the time and [5]. The most important things that happen in life involve work.

\subsection{Measuring OCB}

OCB is viewed as performance that creates enabling social and psychological environment in which completion of assigned duties actually happen (Organ, 1997). The importance of OCB is relatively tricky (Katz \& Kahn, 1978). Because, involve conducts that do not directly relay to duties completion but imperative to aggregate organizational well-being (Bateman \& Organ, 1983). It is indirect as its traditionally discretionary and not overtly documented by any organizational official reward scheme; but facilitates sound operations of an organization (Organ et al., 2006). Examples of OCB include facilitating others at work in terms of unconditional help, completing additional assignments more than what allocated, and defending organizational interests (Bolino \& Turnley, 2003). That is why in better performing organizations; it is custom to incorporate OCB in executing tasks, assisting needy staff, in the course of meeting organizational goals (Amabile et al. 2014). To measure OCB among staff in LGAs; questionnaire designed and developed by Williams \& Anderson (1991) was employed. Empirical evidence suggests the scale indicated good reliability in proceeding studies ie Cronbach's alpha better than .70 (eg. Karriker \& Williams, 2009). OCB data collecting instrument included four items namely: - [1]. I help others who have been absent; [2]. I help others who have heavy work loads; [3]. I take time to listen to coworkers' problems and worries and [4]. I go out of way to help new employees. All scale items were measured on 5-likert scale spreading from [1] Strongly Disagree to [5] Strongly Agree response.

\subsection{Measuring Knowledge Sharing}

Knowledge sharing is a process intended to capture experiences from possessor such that' it transferred to deficit areas (Levitt, \& March, 2008). In other words, it is a knowledge transfer that enhances learning in respective institution. Thus, it defines transfer of knowledge across organizational structure sharing knowledge between employees (Szulansk et al, 2004). Practically, it involves a set of shared experiences pertaining to enabling workers 
access to relevant skills, knowledge and experiences using knowledge systems within an organization (Hogel et al., 2003). Lin (2007) define knowledge sharing as social communication culture, involving give and take knowledge, experiences, and skills in entire organization structure. Importance of knowledge sharing in organization settings is not in dispute. Its availability produces opportunities to exploit organization ability to create solutions that foster competitive advantage in competitive markets (Reid, 2003). It should however be noted that knowledge transfer is individual willingness. Precisely putting, it can't be forced in any way; connotes individual willingness to share acquired skills, experiences and knowledge with co-workers (Gibbert \& Krause 2002). The questionnaire designed and developed by Cheng \& Chen (2007) was employed to measure Knowledge sharing desire on three constructs. An instrument had previously recorded sufficient psychometric properties ie. Cronbach's alpha better than .70 (eg. Karriker \& Williams 2009). As said earlier; Knowledge Sharing was made up of three constructs namely: - [1]. I will, depending on necessity, share with others any knowledge obtained from other members in the organization; [2]. I will immediately share with my good colleagues any knowledge obtained from other members in the organization and [3]. I will share knowledge with my good colleagues using e-mail. All scale items were measured on 5-likert scale spreading from [1] Strongly Disagree to [5] Strongly Agree response.

\subsection{Data Analysis and Interpretation}

Data analyses and interpretation employed Hayes and Mod-Graph Approaches to analyse and test OCB moderation. While earlier approach provides just conditions essential to suggest moderation (Hayes, 2004); the latter provide the actual size of the moderation and confirmation (Jose, 2013). With Hayes; Moderation can be revealed if it is vivid that; the nature of relationship between two variables of interest varies as the values of moderating variable vary (Hayes, 2004). This is executed by creating two regression models. The first regression model contains independent variable (Job Involvement-JI) and moderator variable (OCB). The second regression model comprise of independent variable, moderator variable and interaction term (JI*OCB). This is executed by introducing in the model an interaction variable and observes changes in the model variance (if any). Indeed, observation focus on checking if the interaction is significant; and that variance determined in the response variable is better than before introduction of interaction variable. The two regression models (first and second) are described in subsequent section.

First Regression model: Regression model is fitted determining Knowledge sharing from Job Involvement and $\mathrm{OCB}$, the proposed moderator. Principally, this is the model without interaction term (Job Involvement*OCB) and it sets a basis for comparison in the second block. Importantly, the effect and the model itself $\left(\mathrm{R}^{2}\right)$ must be significant. As a point of note; first regression model was employed to test variances caused by Job Involvement and OCB in Knowledge sharing levels. Observed variances were taken as comparison foundation in determining moderation in the second regression model. Second Regression model: Regression model was fitted determining Knowledge sharing from Job Involvement, OCB and Involvement*OCB. The difference here was that; interaction term $(\mathrm{JI} * \mathrm{OCB})$ was introduced in the model. The focus was to check if at all there was significant difference in the model; following introduction of interaction term in the first model. In this case not only the model is checked its significance but also significance in $\mathrm{R}^{2}$ change. In the second regression model; it's when moderation analysis was tested. Literally, it estimated moderation through putting onto the second regression model; the product term 
of two variables as predictor variable (Gatignon \& Osgerau 2006). The effect of independent variable; in this case, depends on the degree of strength in moderator variable. That said; product term facilitated in describing the natures of predictor-outcome association either (Preacher et al, 2007).

Generally, Regression model interpretation was based on two scenarios. In the first scenario; when JI and OCB were not significant with the interaction term (JI* OCB) introduced in the model. This could be interpreted as absolute moderation. Second scenario is when Job Involvement and OCB were significant with the interaction term introduced in the model. This could be interpreted as moderation existed parallel with main effect influence. Specifically, estimations interpretation were based on four steps:- [1]Demonstrate that regression model one (before introducing product term) is significant; [2]Demonstrate that regression model two (after introducing product term) is significant; [3]Demonstrate that regression model two explain adequately more variance in outcome variable than model one; [4] If step three is in affirmative; then moderation is likely to occur between independent and dependent variable. Traditionally, procedures for analyzing moderation (full or partial) provide just conditions essential to suggest moderation in the model (Hayes, 2004). They don't provide the actual size of the moderation (Jose, 2013). Consequently, Mod-Graph Analysis as recommended by Jose (2013) was made part of the analysis for further moderation confirmation. Basically, Mod-Graph analysis result into graphical presentation following internet Mod-Graph version calculation of cell means. It offers a far better overly picture related to enhancing role that OCB plays in the Job Involvement - Knowledge Sharing relationship.

\section{Results and Discussion}

\subsection{Reliability Analyses}

Prior to actual data analysis; scales reliability analyses were conducted as proposed by Nunnally, (1978) and Briggs \& Cheek, (1986). According to Nunnally, scale reliability can be checked using internal consistency which is the degree to which the constructs hang together. Simply putting, it is the degree to which constructs in the scale are measuring the targeted variable. Cronbach alpha values better than .70 is recommended for sound internal consistency. An inspection of Cronbach alpha values in Job Involvement, Knowledge Sharing and OCB instruments indicated good scale internal consistency by observing values better than .70. Thus, Reliability analysis results indicated all the three scales had acceptable Cronbach alpha values [Job Involvement (.73), Knowledge Sharing (.70) and OCB (.80)]; suggesting scales were suitable for data collection. Contrary, Briggs \& Cheek propose an alternative scale internal consistency to be mean inter-item correlation for the constructs. Mean inter-item correlation values falling between .2 and .4 suggested better scale internal consistency. An assessment of Corrected Item-Total Correlation column revealed no values worse than .2; suggesting the degree to which each construct correlate with the total score is practically significant.

\subsection{Regression Analysis}

In retort of research question one; that focused in investigating the nature of Job Involvement and Knowledge Sharing association; regression analysis was employed. Chiefly, regression analysis facilitates and allows researchers to know the level of variance in dependent variable explained by independent variable (Levin \& Rubin, 2006). Precisely putting; it suggests contribution of independent variable in predicting levels of dependent variable. 
Eventually, Regression model was fitted to the collected data and the same was used to predict values of Knowledge Sharing from Job Involvement as predictor variable. Results in table 1, indicates regression model predicted Knowledge Sharing considerably and significantly well as supported by F $[(1,394)=329.439, \mathrm{P}<.005]$

Table 1: Analysis of Variance

\begin{tabular}{|c|c|c|c|c|c|c|}
\hline & Model & $\begin{array}{l}\text { Sum } \\
\text { Squres }\end{array}$ & $\mathrm{df}$ & Mean square & $\mathrm{F}$ & Sig. \\
\hline 1 & Regression & 824.332 & 1 & 824.332 & 329.439 & .000 \\
\hline & Residual & 985.878 & 394 & & & \\
\hline & Total & 1810.210 & 395 & & & \\
\hline $\mathrm{R}$ & .675 & & & & & \\
\hline $\mathrm{R}^{2}$ & .455 & & & & & \\
\hline Adjusted $\mathrm{R}^{2}$ & .454 & & & & & \\
\hline Beta & .675 & & & & & \\
\hline Part Corr. & .675 & & & & & \\
\hline
\end{tabular}

P-value .000 pointed out that regression model was significant in explaining Knowledge Sharing levels contributed by Job Involvement. Again, $\mathrm{F}$ value 329.439 , at 5\%, specifies that critical $\mathrm{F}$ is greater than $\mathrm{F}$ calculated; allowing conclusion that overall model was soundly significant. R .675 revealed relatively high degree of positive correlation (Cohen, 1988) while $\mathbf{R}^{2}$ value .455 indicated $45.5 \%$ of variation in Knowledge Sharing was contributed by Job Involvement; which is considerably great variance. It can therefore be said; there is positive relationship between Job Involvement and Knowledge Sharing. That is to say; both Job Involvement and Knowledge Sharing increases and decreases in tandem. In other words; when employees have sound Job Involvement desire at work; they tend to place higher importance in Knowledge Sharing behaviour to other employees. Such results are consistent with previous studies for instance; Eman \& Din (2015); and Probst (2000); who reported Job involvement to impact Knowledge sharing on positive fashion. Perhaps, this is due to nothing but Job Involvement desire instil, in employees, psychological identification with respective work and/or turn work into individual's identity (Lodhal \& Kejner, 1965). Psychological identity in this respect augments work motivation that unlocks berries in knowledge sharing (Fletcher, 1998). Further; these results are consistent with TRA reasoning.

In TRA perspectives; employees' chance to execute a certain behavior is robust when they possess favorable attitude towards execution of respective behavior. Thus, positive attitude towards Job Involvement should be sound predictor of knowledge sharing intent and respective actual Knowledge Sharing behavior. On TRA application rapports; JI positive impact on KS results; matches TRA reasoning as advanced by Ajzen \& Fishbein, (1980). Positive JI involvement attitude should form favorable attitude towards not only knowledge sharing intention; but also, to actual knowledge sharing to other employees. The argument is based on the fact that; employee's choice as to engross in certain behavior is dictated by intent to execute the behavior; which originate from subjective norm and attitude on the behavior under considerations (Yu et all., 2010). In other words; employees' choice to share knowledge they possess; is dictated by intent to share knowledge; which originate from positive Job Involvement attitude.

\subsection{Hierarchical Regression Analysis}

In response to research question two; Hierarchical Regression Analysis was conducted as per Hayes (2004). Second research question wanted to know as to whether, or not, Organizational Citizenship Behaviour (OCB) play 
an enhancing/moderating role in Job Involvement - knowledge sharing relationship? According to Hayes; moderation is to the effect that; when moderating variable is introduced to the crafted regression model; it modifies the direction or size of the association between predictor and outcome variable. In this respect; regression model one (before introducing product term) was conducted where Job Involvement - Knowledge Sharing relationship was the case. $\mathrm{F}(1,394)=329.439, \mathrm{P}<.005$ Suggested that regression model one was significant and thus moderation estimation step one was satisfied. In the same vein; regression model two (after introducing product term) was conducted. It included third variable (OCB) in Job Involvement - Knowledge Sharing relationship; making a product term $\mathrm{JI} \times \mathrm{OCB}$. Results in table 2 indicated model two was, significant as well $(\mathrm{F}(1,393)=$ $230.640, \mathrm{P}<.005)$ and therefore the second parameter for moderation was satisfied. In step three; regression model one and two were compared to discover; whether or not; regression model two registered more variances. Results in table 2 indicates $\mathrm{R}^{2}$ change $.085, \mathrm{p}=.000$; proposing or extending moderating effect hint in Job Involvement Knowledge Sharing relationship. Hierarchical regression; in this case; addressed reported TRA weaknesses such as sufficiency of attitudes and subjective norms to explain behavioral intentions and actual behavior (Hagger, 2019). OCB introduction in the model genuinely addressed reported sufficiency and simplicity issues; as it reinforced intention-behavior relationship (Sheeran \& Conner 2017)

Table 2: Moderation Analysis

\begin{tabular}{|c|c|c|c|c|c|c|c|}
\hline & Model & $\begin{array}{l}\text { Sum of } \\
\text { Squares }\end{array}$ & Df-1 & Df-2 & $\begin{array}{l}\text { Mean } \\
\text { square }\end{array}$ & $\mathrm{F}$ & Sig. \\
\hline \multirow[t]{3}{*}{1} & Regression & 824.332 & 1 & 394 & 824.332 & 329.439 & .000 \\
\hline & Residual & 985.878 & 1 & 393 & 2.502 & & \\
\hline & Total & 1810.210 & & & & & \\
\hline \multirow[t]{4}{*}{2} & Regression & 977.447 & & & 488.724 & 230.640 & .000 \\
\hline & Residual & 832.762 & & & 2.119 & & \\
\hline & Total & 1810.210 & & & & & \\
\hline & 1 & 2 & & & & & \\
\hline $\mathrm{R}^{2}$ & .455 & .540 & & & & & \\
\hline Adjusted $\mathrm{R}^{2}$ & .454 & .538 & & & & & \\
\hline \multicolumn{8}{|l|}{ Beta } \\
\hline \multicolumn{8}{|l|}{ Part Corr. } \\
\hline $\mathrm{R}^{2} \boldsymbol{\Delta}$ & .455 & .085 & & & & & \\
\hline
\end{tabular}

\subsection{Mod-Graph Analysis}

Despite hierarchical regression moderation effect clues (indicated in table 1); this study took a step further to confirm indicated moderating effect. In that response; Mod-Graph Analysis was conducted to additionally confirm suspected moderating effect in the Job Involvement - Knowledge Sharing relationship. Conferring Jose (2013); Mod-Graph analysis program enables researchers to introduce statistical data collected from regression analysis; into Mod-Graph program to uncover statistical interactions presented in graph form. Primarily, it serves as the confirmation analysis following hint offered by hierarchical regression analysis.

Inspection of figure 1(Mod-Graph moderation analysis), suggested individuals with all levels of OCB reported improved desire to Knowledge Sharing as Job Involvement increases (OCB lines High, Medium and Low). Further, visual assessment of the graph; suggests; even at lower levels of Job Involvement; employees with higher levels of OCB reported higher levels of Knowledge sharing as well (Figure 1). Putting into other words; improving 
OCB; improves the effect of Job Involvement on Knowledge sharing either. Upward opening of the three OCB lines as Job Involvement improves; is in conformity with Hayes claims that introducing moderating variable in the model; changes the magnitude of relationship. Consequently, it is safe, therefore, to suggest; OCB moderated Job Involvement - Knowledge sharing relationship at enhancing fashion. Thus, increasing OCB would increase the effect of Job Involvement on desire to Knowledge sharing. This is consisted with preceding findings such as Teh \& Sun (2012) who found OCB to play an enhancing role in Job Involvement - Knowledge sharing relationship. Apparently, Job Involvement - Knowledge sharing relationship is sturdy when employees are high in OCB. Significant Job Involvement impact on Knowledge sharing; takes indirect rout through OCB.

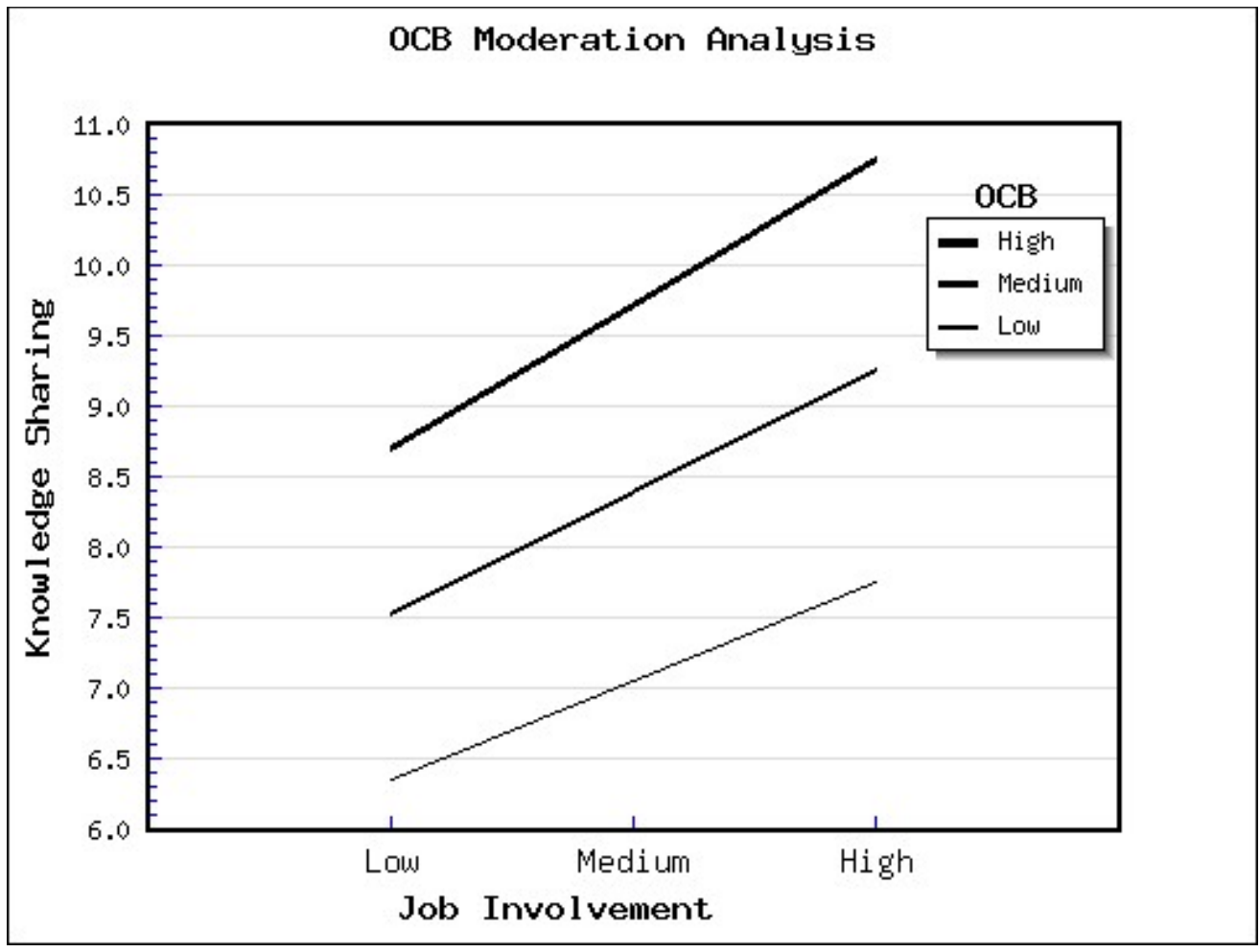

Figure 1: OCB Moderation Analysis

\section{Conclusions and Implications}

\subsection{Conclusions}

This study worked on three research questions namely One: What is the nature of relationship between Job Involvement (JI) and Knowledge Sharing (KS)? Two: Does Organizational Citizenship Behaviour (OCB) play moderating role in Job Involvement - Knowledge Sharing relationship? And Three: What are the TRA extension remedies? (if any). The following are the conclusions drawn by this study: -

1. The nature of relationship between Job Involvement (JI) and Knowledge Sharing (KS) was found to be positive in nature; supporting previous studies such as Rehman et al., (2011); Probst (2000); Eman \& Din (2015) and Ten \& Sun, (2011). They maintained; Job Involvement may lead employees acquire self-confidence and influence to share possessed work knowledge as opposed to inadequate job involvement employees. Findings to this study indicated Job Involvement and Knowledge Sharing; both 
change in tandem. That is; it changes in the same direction such that; increase in JI leads to increase in KS. The same way; decrease in JI would lead to poor KS at work place.

2. The question as to whether or not; Organizational Citizenship Behaviour (OCB) play moderating role in Job Involvement - Knowledge Sharing relationship was in affirmative. The study found; the relationship between Job Involvement and Knowledge Sharing depend on the third variable namely OCB. Conceivably, OCB affects the strength of the Job Involvement - Knowledge Sharing relationship; such that the relationship registered more variances (in KS) when OCB was put in the model operation. That said, OCB strengthen, diminish, negate, or otherwise alter the Job Involvement - Knowledge Sharing association. On previous studies terms; is supports findings for authors including Hoshyar et al, (2017); Teh \& Sun (2012); Ueda (2011); Thiagarajan \& Kubendran (2012); and Eman \& Din (2015)

3. TRA has been intensively used to predict Knowledge Sharing behavior. Nevertheless, it has received adequate application criticism including sufficiency in predicting behavior. Fundamental characteristics of Theory of Reasoned Action (TRA) in its relative economy, meanness and weakness while determining behavior variances across cultural context. This was interpreted as simplicity and lack of capacity in TRA to determine or predict behavior vigorously. Researched findings have proposed extension of TRA by incorporating additional constructs, variables or processes in the mission to craft a more comprehensive prediction of behavior. This study extended TRA model by introducing moderating variable $(\mathrm{OCB})$ in the attitude - intention -knowledge sharing causal relation with the mission of reducing sufficiency, simplicity and lack of capacity issues. Moderators' incorporation responds to the call of doing so by authors, but not limited to Sheeran \& Webb (2016); Van-Bree, et al. (2013); Sheeran \& Conner (2017).

\subsection{Implications for practices}

This study offered one of the landmark empirical tests of the Job Involvement - Knowledge sharing relationship; a moderating role of OCB in Tanzanian LGAs using TRA model. It makes several practice implications including:

1. This study approached Job Involvement as knowledge sharing predictor with respect to employees' actual sharing behavior influenced by intention to do so. In fact, findings established Job Involvement and Knowledge Sharing are positively related in nature. Respondents' scores were significantly higher for Job Involvement causing higher variances in Knowledge Sharing behavior. In other words, Job Involvement explained significant and unique variances in Knowledge Sharing behavior. In practice terms; LGAs human resource practitioners should concentrate in developing or maintaining more enriching job environment that attract employees Job Involvement. This could be a valuable ground to enhance public servants' Job Involvement as well as Knowledge Sharing desire.

2. The study model designed in this study is of worth in two imperative ways. First, it contributes to theorizing on the moderating role of OCB in predicting Knowledge among public servants; LGAs in 
particular. Second, it adds value to the empirical evidence in the domain of the respective constructs under the research, as it analyses the moderation of OCB in the hypothesized linkage between Job Involvement and Knowledge Sharing. Findings suggest management and supervisor's support in creating positive attitude (Teo, 2005) for example JI, OCB etc is central. In practice ramifications; public service should reward managers and supervisors for providing support in developing and maintaining both Job Involvement and OCB among public servants

3. The study model that incorporated moderator variable into TRA model in this study is of worth in several parameters: In particular; it adds value to the empirical evidence in the domain of TRA lacking constructs reported as critics to the model that put into questions its vigorousness in predicting behavior. It did so by analyzing the moderation of OCB in the hypothesized linkage between attitude/subjective belief and Knowledge Sharing. As remedy; researchers proposed TRA model to introduce OCB variables (moderator) into the model that may strengthen variances in intentionbehavior relationship. In other words, TRA model to incorporated moderator variable to address simplicity, insufficiency and variance adequacy issues (Sheeran \& Webb (2016); Van-Bree, et al. (2013); Sheeran \& Conner (2017).

\subsection{Implications for Future Researches}

The results of this study should be taken in light of few noted limitations, which may not blow findings worthiness in any way. Incorporation moderator variable into TRA model in this study; was done in LGAs based data. It is risky to generalize these findings in entire Tanzanian public service. It is proposed; therefore, the designed theoretical model of this study should be tested in other public service settings, such as Central Government, Parastatal, Executive Agencies, and State Owned Enterprises etc.

This study surfaced various directions for future studies in two dimensions. First: longitudinal research is proposed as it would add value to deduce causal associations of Job Involvement and Knowledge Sharing behavior in public servants. Second: it is of essence to collect responses from employees in top management, middle management and lower management as well, public service. This would reduce bias risk and inclusion issues pertaining to management and professional groups in public service. Again; similar to previous studies in this area; questionnaire in self-reporting fashion was opted to collect data. This might have limited the deductions reached about causality and also registers questions about common method bias. Much as findings to this study are consistent with other previous findings; it is likely that Job Involvement positively determine Knowledge Sharing with OCB moderating the relationship either.

\section{References}

Aliakbar et al, (2012); Determinants of Knowledge Sharing Behavior; International Conference on Economics, Business and Marketing Management IPEDR vol.29

Ajzen, I., \& Fishbein, M. (1980). Understanding attitudes and predicting social behavior. Engelwood Cliffs, NJ: Prentice Hall. 
Amabile, T., Fisher, C. M., and Pillemer, J. (2014). IDEO’s culture of helping. Harvard Bus. Rev. 92, 54-61

Bailey, J. (2012), "Informal screencasting: results of a customer-satisfaction survey with a convenience sample", New Library World, Vol. 113 Nos 1-2, pp. 7-26.

Bateman, T. S., \& Organ, D. W. (1983). Job satisfaction and the good soldier: The relationship between affect and employee "citizenship". Academy of Management Journal, 26(4), 587-595. doi:10.2307/255908

Baron, R.M. and Kenny, D.A. (1986), "The moderator-mediator variable distinction in social psychological research: conceptual, strategic, and statistical considerations", Journal of Personality and Social Psychology, Vol. 51 No. 6, pp. 1173-82.

Bolino, M.C., Turnley, W.H. and Bloodgood, J.M. (2002), "Citizenship behaviour and the creation of social capital in organizations”, Academy of Management Journal, Vol. 27 No. 4, pp. 505-22.

Bolino, M. C., and Turnley, W. H. (2003). Going the extra mile: cultivating and managing employee citizenship behavior. Acad. Manag. Perspect. 17, 60-71. doi: 10.5465/ame.2003.10954754

Bock, G. W., Zmud, R. W., Kim, Y. -G. and Lee, J. -N. (2005). Behavioural intention formation in knowledge sharing: Examining the roles of extrinsic motivators, social-psychological forces, and organisational climate. MIS Quarterly, 29(1), 87-111.

Bogler Ronit \& Somech Anit (2005); Organizational citizenship behavior in school; How does it relate to participation in decision making? Journal of Educational Administration Vol. 43 No. 5, pp. 420-438

Blanchard, A. \& Markus, M. (2004) 'The experienced "sense" of a virtual community:

characteristics and processes', The DATA BASE for Advances in Information Systems, Vol. 35, No. 1, pp.65-79.

Carson, K.D., Carson, P.P. and Bedeian, A. G. (1995), "Development and construct validation of a career entrenchment measure", Journal of Occupational and Organizational Psychology, 68: 301-20

Chiu, C-M., Hsu, M-H. and Wang, E. (2006) 'Understanding knowledge sharing in virtual communities: an integration of social capital and social cognitive theories', Decision SupportSystems, Vol. 42, pp.1872-1888.

Collins, C. J., \& Smith, K. G. (2006). Knowledge exchange and combination: The role of human resource practices in the performance of high-technology firms. Academy of Management Journal, 49(3), 544-560

Dennis, A. (1996). ' Information exchange and use in group decision making: you can lead a group to information, but you can't make it think', MIS Quarterly, Vol. 20 No. 4, pp. 433-55.

Fishbein, M., \& Ajzen, I. (2011). Predicting and changing behavior: The reasoned action approach. New York: Psychology Press.

Fishbein, M. \& Middlestadt, S.E. (1989). Using the theory of reasoned action as a framework for understanding and changing AIDS-related behaviours. In V.M. Mays, G.W. Albee \& S.F. Schneider (Eds.), Primary prevention of AIDS: Psychological approaches (pp. 89 - 110). Newbury Park: Sage

Fishbein, M. and Ajzen, I. (1975). Belief, Attitude, Intention, and Behaviour: An Introduction to Theory and Research. Addison-Wesley, Reading, MA.

Fishbein, M. (1993). Introduction by Martin Fishbein. In D.J. Terry, C. Gallois \& M. McCamish (Eds.), The theory of reasoned action: Its application to aids preventive behaviour (pp. xv - xxv). Oxford: Pergamon Press.

Gibbert, M. and Krause, H. (2002), "Practice exchange in a best practice marketplace", in Devenport, T.H. and Probst, G.J.B. (Eds), Knowledge Management Case Book: Siemens Best Practice, Wiley, Berlin, pp. 89-105 
Hagger, M. S. (2019). The reasoned action approach and the theories of reasoned action and planned behavior. In D. S. Dunn (Ed.), Oxford Bibliographies in Psychology. New York, NY: Oxford University Press. doi: 10.1093/OBO/9780199828340- 0240

Hogel, M., Parboteeah, K.P. and Munson, C.L. (2003), “Team-level antecedents of individuals' knowledge networks", Decision Sciences, Vol. 34 No. 4, pp. 741-70.

Hoshyar et al, (2017): The Effect of Job Attitudes on Knowledge Sharing Behavior by Examining; The Mediating Role Of Organizational Citizenship Behavior; 13th International Conference on Knowledge, Economy \& Management Proceedings

Hsu, C.L. and Lin, J.C.C. (2008), “Acceptance of blog usage: the roles of technology acceptance, social influence and knowledge sharing motivation”, Information \& Management, Vol. 45, pp. 65-74.

Hsu, M-H., Ju, T.L., Yen, C-H. and Chang, C-M. (2007) 'Knowledge sharing behavior in virtual communities: the relationship between trust, self-efficacy, and outcome expectations', International Journal of Human-Computer Studies, Vol. 65, pp.153-169.

Hwie Seo, P. \& Byung-Choon, I. (2003). “A Study on the knowledge sharing Behavior of Local Public Servants in Korea: A Structural Equation Analysis." Available at http://kapa21.or.kr/data/daadownload.php?did=1022 (Accessed on 24/09/2020).

Jeppesen, L. \& Frederiksen, L. (2006) 'Why do users contribute to firm-hosted user communities? The case of computer-controlled music instruments', Organization Science,

Vol. 17, No. 1, pp.45-63.

Joiner, T. A., \& Bakalis, S. (2006). The antecedents of organizational commitment: The case of Australian casual academics. International Journal of Educational Management, 20, 439-452.

Jose, P.E. (2013). ModGraph-I: A programme to compute cell means for the graphical display of moderational analyses:The internet version, Version 3.0. Victoria University of Wellington, Wellington, New Zealand. Retrieved on September, 2018 from https://psychology.victoria.ac.nz/modgraph/

Kanungo, R.N. (1982). Measurement of job and work involvement. Journal of Applied Psychology, 67(3), 341349.

Katz, D. and Kahn, R.L. (1978), The Social Psychology of Organizations, Wiley, New York, NY

LaCaille, L. (2013). Theory of Reasoned Action. In M. Gellman \& J. Turner (Eds.), Encyclopedia of behavioral medicine (pp. 1964-1967). New York: Springer.

Lee, J. (2005). The Impact Of Knowledge Sharing, Organizational Capability And Partnership Quality On IS Outsourcing Success. Information \& Management, (38:5), pp. 323-335.

Lee, Y., Kozar, K.A dan Larsenm K.R.T (2003). The Technology Acceptance Model: Past, Present and Future. Communication of the Association for Information System (12;50) pp 752-780

Lin Hsiu-Fen (2007): Knowledge sharing and firm innovation capability: an empirical study; International Journal of Manpower Vol. 28 No. 3/4, 2007 pp. 315-332

Mahmood A., M.A. Qureshi \& Q. Shahbaz, (2011); An Examination of The Quality of Tacit Knowledge Sharing Through the Theory of Reasoned Action; Journal of Quality and Technology Management Volume VII, Issue I, pp, 39 - 55

Montano, D. E. \& Kasprzyk, D. (2002). The theory of reasoned action and the theory of planned behaviour. In K. Glanz, B. K. Rimer, \& F. M. Lewis (Eds.), Health behaviour and health education: Theory, research and practice (pp. 67 - 98). San Francisco: Jossey Bass.

Nonaka, I. \& Takeuchi, H. (1995). The Knowledge-Creating Company. New York. Oxford University Press. 
Organ, D.W. (1997), Organizational Citizenship Behavior: The Good Soldier Syndrome, Lexington Books, Lexington, MA.

Peslak, A., Ceccucci, W., \& Sendall, P. (2012). An empirical study of social networking behavior using Theory of Reasoned Action. Journal of Information Systems Applied Research, 5(3), 12

Podsakoff, P.M., MacKenzie, S.B., Paine, J.B. and Bachrach, D.G. (2000), “Organizational citizenship behaviors: a critical review of the theoretical and empirical literature and suggestions for future research", Journal of Management, Vol. 26 No. 3, pp. 513-63

Rahab \& Wahyuni, (2013): Predicting Knowledge Sharing Intention Based on Theory of Reasoned Action Framework: An Empirical Study on Higher Education Institution; American International Journal of Contemporary Research Vol. 3 No. 1

Röll, M. (2004) 'Distributed KM - improving knowledge worker's productivity and organizational knowledge sharing with weblog-based personal publishing', Paper presented in BlogTalk 2.0 - The European Conference on Weblogs, Vienna, 5-6 July 2004,

http://www.roell.net/publikationen/distributedkm.pdf (retrieved September 2018).

Rehman, M., Mahmood, A.K.B., Salleh, R. \& Amin, A. (2010). "Review of Factors Affecting Knowledge Sharing Behavior", 2nd International Conference on E business, Management and Economics-ICEME, China.

Reid, F. (2003), "Creating a knowledge sharing culture among diverse business units", Employment Relations Today, Vol. 30 No. 3, pp. 43-9.

Salas-Vallina, A., Alegre, J. and Fernandez, R. (2017), "Happiness at work and organizational citizenship behavior: is organizational learning a missing link?”, International Journal of Manpower, Vol. 38 No. 3, pp. 470488

Teo, T. S. H. (2005). Meeting the challenges of knowledge management at the Housing and Development Board. Decision Support Systems, 41(1), 147-159. Tett, R. P., \& Burnett, D. D. (2003). A personality trait-based interactionist model of job performance. Journal of Applied Psychology, 88(3), 500-517.

Tlou E. R (2009): The Application of The Theories Of Reasoned Action and Planned Behaviour to a Workplace Hiv/Aids Health Promotion Programme; Thesis, University of South Africa

Wagner, C. \& Bolloju, N. (2005) 'Supporting knowledge management in organizations with conversational technologies: discussion forums, weblogs, and wikis', Journal of Database Management, Vol. 16, No. 2, pp.1-8.

Wang \& Noe (2010); Knowledge sharing: A review and directions for future research; Human Resource Management Review 20, pp, 115-131

Yu, A., Hao, J., Dong, X. and Khalifa, M. (2010) 'Revisiting the effect of social capital on knowledge sharing in work teams: a multilevel approach', International Conference on Information Systems (ICIS) Proceedings, AISeL. 